Masculinidad en el libro vacío y los años falsos

de Josefina Vicens.

Masculinity in the empty book and the false years

Josefina Vicens.

Adriana Sáenz Valadez

EL CAUSANTE DE LA VIOLENCIA

(DOMINANTE): EL JAGUAR DE LA

CIUDAD Y LOS PERROS (1963) DE MARIO

VARGAS LLOSA

THE CAUSER OF VIOLENCE (DOMINANT):

THE JAGUAR IN THE TIME OF THE HERO

(1963) BY MARIO VARGAS LLOSA

JOSÉ MIGUEL DELGADO DEL AGUILA

Identidades de Género en las Telenovelas

Mexicanas: estudio de caso de La Candidata.

Gender Identities in Mexican soap operas: case

study of La Candidata.

Anna María Fernández Poncela

Martha Estela Pérez García 


\section{AMOR ROMÁNTICO ENTRE ESTUDIANTES UNIVERSITARIOS (HOMBRES Y \\ MUJERES), UNA MIRADA DESDE LA PERSPECTIVA DE GÉNERO. \\ ROMANTIC LOVE BETWEEN UNIVERSITY STUDENTS (MEN AND WOMEN), A LOOK FROM THE GENDER PERSPECTIVE} JORGE GARCÍA VILLANUEVA/CLAUDIA IVONNE HERNÁNDEZ RAMÍREZ Y NÁYADE SOLEDAD MONTER ARISMENDI

\section{Análisis psicosocial de la cultura de género en} estudiantes universitarios

Psychosocial analysis of gender culture in university students

Lorena Aragón Macías

Ana María de Guadalupe Arras Vota

Gerónimo Mendoza Meraz

HUELGAS, MAESTRAS Y RUMORES. UNA ESCENA DE MUJERES EN LUCHA A PARTIR DE UN ESTUDIO DE CASO (FIRMAT, ARGENTINA, 1921) STRIKES, TEACHERS AND RUMOURS. A SCENE OF WOMEN IN STRUGGLE FROM A CASE STUDY (FIRMAT, ARGENTINA, 1921) MICAELA PELLEGRINI MALPIEDI 


\title{
Masculinidad en el libro vacío y los años falsos de Josefina Vicens ${ }^{1}$ \\ Masculinity in the empty book and the false years \\ by Josefina Vicens \\ Adriana Sáenz Valadez ${ }^{2,3}$
}

${ }^{1}$ Agradezco los comentarios que este trabajo recibió en el XII Congreso de Literatura Mexicana Contemporánea. Esta investigación forma parte del proyecto de investigación: Patriarcado y racionalidad patriarcal en los textos culturales mexicanos 2018, inscrito en la Coordinación de la Investigación Científica, UMSNH. Agradezco a la Universidad del País Vasco su invitación como investigadora y su apoyo para la realización de este trabajo.

${ }^{2}$ UMSNh/CONACYT/UPV. México. Correo electrónico: asaenzva@gmail.com

${ }^{3}$ Este trabajo forma parte del proyecto sabático apoyado por CONACYT, 2017-2018 y de la estancia de investigación realizada en la Universidad del País Vasco.

\begin{abstract}
Resumen
Josefina Vicens en sus novelas innovó en el espacio estético en varios elementos. Uno fue al presentar un nuevo tópico que rompía con la temática del movimiento armado, otro cuando presentó nuevos cuestionamientos sobre las familias de la clase media en la Ciudad de México y al exponer dilemas sobre la teoría literaria y el vacío. En este marco podemos decir que también en sus textos reprodujo y cuestionó a la moral patriarcal, donde abordó descriptiva y críticamente las formas de interacción y de reproducción del género. Por ello, para efectos de este análisis se abordan El libro vacío y Los años falsos como textos que proponen nuevos cuestionamientos narratológicos y que a su vez, como
\end{abstract}


tecnologías del género, reproducen y hacen crítica a la masculinidad tradicional. En este texto se analiza el continuo y los cuestionamientos a dicha masculinidad que José García, Poncho y Alfonso Fernández presentan.

Palabras clave: Josefina Vicens, masculinidad tradicional, racionalidad patriarcal, El libro vacío, Los años falsos.

\begin{abstract}
Josefina Vicens in her novels innovated in the aesthetic space in several elements. When presenting a new topic that broke with the theme of the armed movement, when she presented new questions about middle class families in Mexico City and exposing dilemmas about literary theories and emptiness. In this context we can say that in her texts she reproduced and questioned the patriarchal morality, where she approached descriptively and critically the forms of interaction and reproduction of the genre. Therefore, for the purposes of this analysis The Empty Book and The False Years are reviewed as texts that propose new narratological questions and in turn, as technologies of gender, can reproduce and, we say, make criticism of traditional masculinity. In this context, the questions of the aforementioned masculinity are analyzed, which José García, Poncho and Alfonso Fernandez present.
\end{abstract}

Keywords: Josefina Vicens, tradicional masculinity, patriarchal morality, The Empty Book and The False Years.

RECEPCIÓN: 8 DE NOVIEMBRE 2017/ACEPTACIÓN: 19 DE FEBRERO 2018 


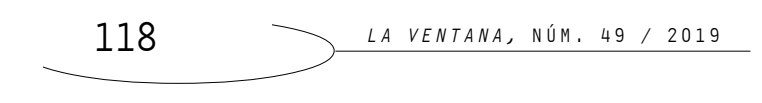

Josefina Vicens en sus novelas innovó en el ámbito de la narrativa en varios aspectos. Uno de ellos, rompió con el tópico del movimiento armado al presentar a las familias de la Clase Media en la Ciudad de México, al exponer dilemas sobre la teoría literaria y el vacío y, de manera paralela, al describir y cuestionar a la moral patriarcal. En sus ficciones, abordó descriptiva y críticamente las formas de interacción y de reproducción del género. Si bien hemos realizado investigaciones sobre su obra, en esta ocasión, el énfasis

${ }^{4}$ Ahora prefiero llamar de género, dado que se han incluido corpus y variables a la es otro aspecto desde la crítica literaria de género: ${ }^{4}$ las masculinidades. La autora en su primera novela, El libro vacío, afrontó el conflicto del autor acerca de los temas que deben ser contados, las formas de hacerlo, el vacío de un ser que se percibe simple y en ello el cuestionamiento a las masculinidades patriarcales, que entre otros elementos, se afirman sobre la negación a la elección. En su segunda novela, el énfasis crítico descriptivo se concentra en la educación que reproduce al sistema patriarcal, en donde las masculinidades son puestas en cuestión.

Por ello, en el marco de las investigaciones donde hemos estudiado a la moral patriarcal, expuesta en las ficciones, en este artículo se analizan las novelas de la autora a partir

${ }^{5}$ Para un referente sobre los estudios sobre las masculinidades en México, véase: Núñez, Guillermo. (2016). "Los estudios de género de los hombres y las masculinidades en México: reflexiones sobre su origen" en La Ventana. Guadalajara, México: Vol. 23, Núm. 19, pp. 30-61. de proponer que innovó en términos narratológicos y de manera paralela, al igual que reprodujo e hizo crítica a las masculinidades tradicionales. ${ }^{5}$ Para fines metodológicos este texto se ha dividido en varios apartados. Una primera sección la componen algu- 
nos elementos biográficos, seguido de un módulo en donde se expone la relación entre la literatura como esquema que motiva la reflexión y/o como tecnología del género. En un tercer apartado se exponen brevemente los elementos que componen la novedad narratológica y crítica del patriarcado en las obras de la autora, para después dar pie a los análisis y a las consideraciones finales.

\section{Algunos datos biográficos}

Josefina Vicens nació en Tabasco el 23 de noviembre de 1911 y murió el 22 de noviembre de 1988, en la Ciudad de México, a los casi 77 años. Desde muy joven su actitud inquieta sumada a la crisis económica familiar la llevó a desempeñarse en varios trabajos previos al de la narrativa. Inició atendiendo el negocio familiar, una tienda de ultramarinos en la colonia Roma. Después migró a otros trabajos que la llevarían a la ficción, la representación política y el liderazgo sindical. Para ello fue mecanógrafa, secretaria y burócrata. Posteriormente y de manera oculta, se desempeñó como escritora de críticas tau-

${ }^{6}$ Fue "Secretaria de Acción Femenil de la Confederación Nacional Campesina, también se desempeñó en posiciones ejecutivas en el Sindicato de la Producción rinas. ${ }^{6}$ Fue Vicepresidenta de la Sociedad General de Escritores Mexicanos (SOGEM) y guionista de muchas películas, entre las que destacan Los perros de Dios (1973), Las Hermanitas Vivanco (1958) ${ }^{7}$ y Renuncia por motivos de salud (1975) (Castro, pp.5772). La escritura de ficción comenzó a realizarla muy Cinematográfica, como Presidenta Ejecu-
tiva en el Sindicato de Producción Cinematográfica, Presidenta de la Academia de Ciencias y Artes Cinematográficas y, posteriormente, oficial mayor de la sección de Técnicos del Sindicato de Cinematografistas" (Fernández, 2006).

${ }^{7}$ Este guion lo escribió a partir de un texto de Elena Garro y Juan de la Cabada (Castro, pp.57-72).

joven, aunque ya de manera formal inició en los años cuarenta, a 


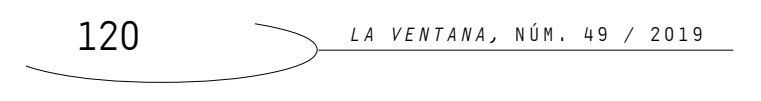

partir de trazar la columna "Farolazos". A partir de travestirse textualmente, firmaba como Pepe Faroles, el cual se convirtió en un referente en el ámbito taurino. Posteriormente, ya como Vicens, escribió dos novelas y un cuento, "Petrita".

Fue una mujer con muchas habilidades tales como atender al dolor de su amigo que le confesaba que no podía asistir al funeral de su padre, porque si lo hacía, tendría que hacerse cargo de la familia y mediante la escucha plasmar esa angustia en Los años falsos. De esta manera, en una obra maestra, hizo una novela que retratara a la moral de la época e hiciera homenaje al querido amigo. Podía char-

${ }^{8}$ A partir de los premios que recibieron las novelas de Vicens se recuperó su figura en elámbito literario. En este sentido destaco dos entrevis tas y que ahora son fuentes documentales para los breves datos biográficos que se presentan. A partir de la guía de Carmen Ramos Escandón Gabriela Cano y Verónica Radkau entrevistaron a Vicens. Véase: Cano, Gabriela y Radkau, Verena. (1989). Ganando espacios. México, UANM-Iztapalapa, pp.79-138 (Correspondencia). La entrevista en dónde Cano y Radkau explican el sentido de las entrevistas que llevaron a cabo a varias escritoras, donde destacan la importancia de la recuperación de la memoria: Cano, Gabriela y Radkau, Verena. (1988). "Lo privado y lo público o la mutación de los espacios (historias de mujeres 1920-1944)". (Consultado el 28 de enero de 2016 en https:/ /ideasfem.wordpress.com/textos/j/j03/). Y González, Daniel y Toledo, Alejandro. (1989). Josefina Vicens: la inminencia de la primer palabra. México: Ediciones sin nombre/Universidad del Claustro de Sor Juana. 2ª edición. lar con los Contemporáneos y al mismo tiempo con los líderes sindicales (Lorenzano, 2006, p.84). Fue como ella decía en la sala de su casa, una mujer que había disfrutado la vida, fue amiga, escritora, líder sindical, crítica taurina y alumna en la Facultad de Filosofía y Letras de la UNAM. ${ }^{8}$ Sus inicios en la escritura, en apariencia simples, evidencian tres elementos que para este análisis son prioritarios, mismos que ella narró. Platicaba que cuando al llegar a trabajar al entonces Departamento Agrario y firmar su entrada, en lugar de suscribir su nombre, lo hacía bajo el pseudónimo que ese día le pareciera interesante: fue Cleopatra, Juana de Arco, Ana Karenina, etc. Lo hacía por tres razones; el primero era que le parecía muy aburrido to- 
dos los días poner el mismo texto, al mismo tiempo deseaba reflexionar sobre los usos y costumbres laborales de la época y porque vivía frenando el deseo de crear otras realidades más allá de las aparentes. Así, la ficción del nombre fue el medio que por breves instantes y de forma simbólica, le permitirían consumar dichos intereses. En palabras de José García, el personaje principal en El libro vacío, los expresa: "¿Cómo puedo adelantar en un libro rígidamente contenido para ocultar esta impotencia de escribir y ésta, mayor aún, de no escribir?" (Vicens, 2006, p.53).

\section{Tecnologías del género y literatura}

En la red de posibilidades que otorgan las ficciones, están aquellas que desde la lectura hermenéutica postula la correlación entre la literatura y moral. Por ello, quiero destacar las siguientes: la de llevar a cabo reflexiones sobre los textos literarios para analizarlos, como los propone la filósofa Teresa de Lauretis, donde la literatura (entre otras narrativas) son pensadas como tecnologías del género. A decir, las ficciones pueden ser estructuras que lleven al lector a la reflexión sobre su subjetividad y también pueden ser mecanismos que coadyuven al proceso del género. Dicho sea, la literatura como producto cultural, representa a la sociedad de la diégesis, y en ello, es también una estructura que puede motivarnos a reflexionar. Los textos de ficción pueden llevar al lector del extrañamiento, al reconocimiento del otro y del sí mismo y en ello, mediante el espiral de deconstrucción, configuración y reconfiguración, reflexionar sobre los actos morales. 


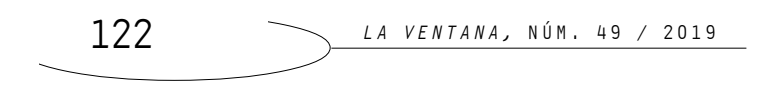

Desde esta perspectiva y desde la lectura de Teresa de Lauretis, quien expone entre otras variables que: "1. El género es una representación. 2. La representación del género es su construcción” (1996, p.9), podemos comprender que el género es una construcción, un continuo, en el que actúan el proceso y la representación. Lo que es, es un estarse haciendo, una representación constante, una vivencia diaria. A su vez, dado que el discurso del género es preexistente al sujeto, y en ello, la racionalidad patriarcal como una razón de razones, un discurso preexistente al sujeto, pos-

${ }^{9}$ Celia Amorós en el libro: Crítica a la razón patriarcal analiza y establece una crítica a dicha razón. En este marco y sólo de manera introductoria, es necesario establecer que si bien el concepto es amplio y su puntualización requiere una reflexión más amplia, podemos asumir que es una razón de razones, que establece configuraciones simbólicas que esencializan a los géneros y establece categorías de valor y del deber ser. Véase: Amorós, Celia.(1991). Crítica a la razón patriarcal. Madrid: Anthropos; Sáenz, Adriana. (2015). "La crítica a la racionalidad patriarcal, un paradigma para pensar a los géneros" en Ávila, Virginia y Suárez, Paola (Coords.) El género y la globalización en los debates de la Teoría Social Contemporánea. México: UNAM, pp.84-109 y Sáenz, Adriana. (2011). Una mirada a la racionalidad patriarcal en México en los años cincuenta y sesenta del siglo xx. Estudio de la moral en Los años falsos de Josefina Vicens. México: UMSNH/Plaza y Valdés. tula nociones que se presentan como estructuras esenciales para los géneros (Amorós, 1991, p.103). ${ }^{9}$ Así podemos decir que el género desde este hacerse es una forma de ser que se aprende, se construye y se participa en su continuo. En este marco lo que Lauretis llama el continuo de las representaciones, y señala que éstas se pueden aprender a partir de los productos culturales, a los que la autora llama tecnologías del género (1996, p.9).

Si bien la autora de Tecnologías del género señala que los productos culturales fungen como tecnologías, también es importante demarcar que si bien los discursos culturales pueden ser tecnologías del género, también pueden de manera dual y concatenada llevar a cabo reflexiones que permitan la deconstrucción del género y sus deberes ser. En este marco las narrativas de ficción en su compleja relación de representación de las formas culturales, pueden fungir varias fun- 
ciones. Una misma ficción puede describir y en ello normar las formas morales (representaciones y deberes ser del género), puede hacer crítica de ello e incluso puede motivar al lector/a a la reflexión, el análisis y la deconstrucción. En este marco, amén de lo dicho, el género es una vivencia continua de las delimitaciones y normas que en el devenir de las representaciones se encarnan y se manifiestan, entre otras formas, a partir de sustratos articulados en términos deontológicos como deberes ser.

\section{Novedad y crítica}

La obra de Vicens fue reconocida y premiada por su propuesta estética. En este marco, podemos destacar los cuestionamientos sobre el vacío y la ruptura con el tema que en la época acaparaba las ficciones, esto es, la Revolución Mexicana. De esta manera, desde sus primeros textos utilizó la prosa poética, incluyó la ironía para cuestionar a la moral y presentó a la Ciudad de México como un nuevo tema y narrador de la diégesis. Ya sea porque presentó una novela sin final, porque los personajes se desdoblan en el momento de enunciación y se crean y recrean de manera dialógica o porque las ficciones están estructuradas como si el interés fuera un conversatorio con la teoría narratológica, pero sin percibirnos de ello, inmersos en el placer cautivante, en la imposibilidad de alejarnos de ellos, los textos proponen y nos cautivan.

La escritura de Vicens mantiene una propuesta estética novedosa, lo que implica no sólo su propuesta narratológica, sino también sus logros a nivel de mímesis crítica. En la escritura logra trenzar los 
${ }^{10}$ En este texto se comprenderá patriarcado como sinónimo de racionalidad patriarcal, en la comprensión que sugiere Sáenz 2011, como una razón de razones que propone demarcaciones sim bólicas en términos de esencias de género. Destaco que el tema de la muerte y la relación con el patriarcado en la obra de Josefina Vicens fue abordado por primera vez en el texto: Domenella, Ana Rosa. (1989). "Muerte y patriarcado en Los años falsos de Josefina Vicens", en Luisa Campusano (coord.). Mujeres latinoamericanas del siglo $\mathrm{xx}$. Historia y cultura. Tomo I. Universidad Autó noma Metropolitana, Iztapalapa/Casa de las Américas, México, pp. 191-204. Para un texto posterior véase: Sáenz, Adriana. (2013). "Los años falsos y El libro vacío: la ciudad, la muerte y los roles de género en Josefina Vicens" en la revista En-cla ves del ser humano del ITESM-CCM. En elNo. 13, pp. 149-174. recursos narratológicos con la crítica a las nociones de la racionalidad patriarcal para los géneros. ${ }^{10} \mathrm{~A}$ saber, la incursión estética de la autora en la escritura evidencia que los textos provocan empatía, educan moralmente y, simultáneamente (de ahí uno de los logros narrativos), llevan a cabo reflexiones sobre la moral patriarcal. A decir, son tecnologías que contribuyen al continuo del género y a su vez, proponen una crítica, para efectos de este estudio a las masculinidades tradicionales que se sustentan en las nociones y deberes ser que la racionalidad patriarcal propone.

Varios son los elementos morales que se explicitan en las obras, para efectos de este estudio, se abordarán dos que participan en la construcción y reproducción de la masculinidad patriarcal, lo que es en el continuo del género. La primera, es aquella que viven los varones en dicha moralidad, la negativa a la elección cuando se trata de optar por un camino que no los postule a partir de los deberes ser de varones de una familia; el segundo, es el reconocimiento que se obtiene a través de la mirada de complacencia, por el cumplimiento del deber, de los/las otros/as, como elementos que participan en la aceptación y la valía.

\section{El libro vacío}

Pero también pienso que si no hablo de él, que ha sido lo mejor de mí, ¿De qué voy hablar? ¿De éste que soy ahora? ¿De éste en que me he convertido? ¿De este hombre 


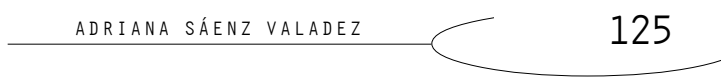

oscuro., liso, hundido en una angustia que no puedo aclarar ni justificar, porque los motivos que lo provocan no son explicables? (Vicens, 2006, p.76)

El libro vacío se publicó por primera vez en julio de 1958 por la Compañía General de Ediciones, S.A. México. Desde su edición, la obra fue reconocida ampliamente por la crítica. En 1963, fue prontamente traducida al francés y editada por Julliard bajo gestión de Alaíde Foppa. De tal que fue merecedora del premio Villaurrutia, cuando el galardón lo otorgaban los ahorros de los escritores. ${ }^{11}$ Posteriormente la novela fue reeditada con una carta prólogo de Octavio Paz, la cual suele acompañar la mayoría de las ediciones siguientes (Lincoln, 2011, p.35). En dicho texto, Paz

${ }^{11}$ Vicens fue la primera mujer en ganar dicho premio y vale decir que los textos finalistas con los que compitió fueron La región más transparente de Carlos Fuentes y Polvo de Arroz de Sergio Galindo, narrativas que también se convirtieron en referentes literarios (Domenella, 1998, p.191). elogia la novela y valora la técnica con la que el tema del vacío está expuesto $(1986$, p.7) y que describe tan vívidamente un mundo tan común para muchos, que él llama, la pequeña burguesía (Paz, 1986, p.7). Dicha característica que el poeta señala, será un sello escritural de la autora de Los años falsos, es decir, la descripción y el análisis de manera simultánea. Mientras incursionamos en el mundo de José, a partir de la diaria escritura del cuaderno uno, aquel que nunca se leerá y que es, "realmente" el que el lector lee, somos invitados de primera fila a la representación del sello estético de la escritura de Vicens, esto es, la reproducción vívida de una moral que hemos llamado patriarcal, y a los pensamientos y actos de un hombre inmerso en ésta. 


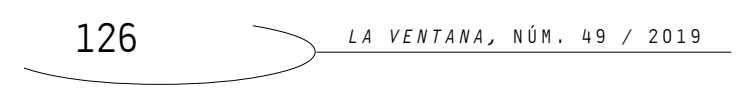

José García, es uno de tantos, pero a su vez es tan personal. A través de escucharlo quedamos perplejos ante la identificación y la comprensión que tenemos de sus reflexiones. No nos quedan ajenas sus razones, ni sus sentidos, su dolor y su contradicción. Es uno de tantos, y a su vez es uno y tantos.

Retomando las ideas que Paz marcó en el prólogo, volvamos a uno de los objetivos de este artículo. Vicens, incursionó en su primera novela con dilemas como el texto en blanco. El cuestionamiento sobre el ser cotidiano, sobre la vida de un burócrata, la no heroicidad de un jefe de familia y los temores ocultos que los hom-

${ }^{12}$ La masculinidad tradicional se sustenta en supuestos como la fuerza, la violencia, el dominio, la dureza la agresividad. Véase: Thompson, Cooper. (2005). "Debemos rechazar la masculinidad tradicional" en Ser hombre. Barcelona: Kairós, Biblioteca de la Nueva Conciencia, $4^{a}$ edición, pp. 28-38. ben callar. Esta obra narra las contradicciones que iluminan el día a día de José García, quien vive esperando la hora de entrada al trabajo, para huir de la vida familiar y el tono del reloj que marca el tiempo final de la jornada para sentarse a tratar de no escribir y vivir deseando hacerlo. Dualidades de su diario existir. Vive entre dos nebulosas que se tejen por los hilos del deber ser. La masculinidad tradicional que lo configura bajo el deber ser de proveedor y hombre que debe contar con la mirada de reconocimiento de quienes lo rodean. Así, el sueño de ser reconocido por su obra, la angustia de no tener nada qué contar, la vida laboral y su anonimato se entretejen para evidenciarle que su vivencia dista mucho del prototipo del deber ser de dicha masculinidad, lo que lo frustra, enoja y lo mantiene en el hilo del intento por cumplir. 
El sello estético de la autora, las voces, las descripciones breves, pero marcadas de elementos nos permiten como lector concretizar ${ }^{13}$ emociones, decisiones, razones. Las situaciones que delinean la diégesis están inmersas en el marco de una racionalidad que nos es comprensible, a partir de lo cual el/la lector/a concretiza

${ }^{13}$ El término concretizaciones lo estoy asumiendo a partir de la propuesta de Roman Ingarden, donde propone que el lector a partir de su ser histórico interpreta los espacios de opalescencia que toda obra literaria contiene. Véase: Ingarden, Roman. (1998). La obra de arte literaria. México: situaciones comunes, lo que permite que la empatía se deslice entre el/la lector/a y el personaje. Historias de la vida, decisiones que desnudan al ser y lo presentan angustiado, confundido, falsamente esperanzado con la felicidad, conformado en vivir pedacitos de luz que él marca como situaciones de tranquilidad. Fragmentos de luz para ocultar que es un hombre inmerso en el deber ser de la masculinidad patriarcal. José cuenta que tuvo que asumir la vida que los padres decidieron para él. La frustración que le amanece, donde el continuo del proceso del género cobra cada día los pedazos de vida que él debe pagar, para poder representar de la mejor manera la masculinidad que en la inocencia de la pubertad creyó lo haría feliz.

José deseaba ser marinero. Se imaginaba dueño de las olas, vestido en su elegante uniforme, adornado con botones recién lustrados y las botas que con su firmeza apuntalaban los pasos. Se veía ceñido con sus agujetas bien acordadas, aquellas que sostienen el hombre que las lleva puestas. Adolescente de las ilusiones, pensó que podía echarse al agua, conquistar y tejer su futuro, pero con lágrimas comprendió que eso no sería para él. Cuando les comunicó a sus padres sus sueños, vislumbró que sus decisiones sólo conta- 


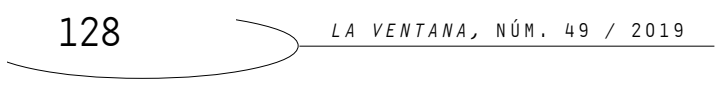

rían con el reconocimiento familiar si elegía optar por reproducir la moral patriarcal. Para ello, dos son los mecanismos morales que apuraron la decisión; el primero, la búsqueda del

${ }^{14}$ Véase: Castellanos, Rosario. (2006) "Los hijos una propiedad privada" en (Reyes, Andrea) (compiladora). Mujer de palabras. Artículos rescatados de Rosario Castellanos. Volumen II. México: CONACULTA, Lecturas Mexicanas, pp.238-241. reconocimiento familiar, el segundo la culpa de no cumplir con el molde del hijo imaginario que los padres se habían configurado. ${ }^{14}$

Recuerdo, por ejemplo, mi decisión de ser marino. Nada en el mundo me hará cambiar de idea — pensaba yo entonces-. (...) Mi padre, en cambio, pronunció un dramático discurso del que sólo pude entender que yo era el único hijo hombre, la esperanza de su vejez y el protector de mis hermanas. Recuerdo que a medida que mi padre hablaba me invadía una especie de asfixia: por lo que sentí el horror de estar encarcelado, condenado sin remedio (...).

Sollocé inconsolable por lo que se me moría, antes de vivirlo. Sin saberlo, creyendo que lloraba por mí, en realidad lloraba por los dos más agrios dolores del hombre: el amor y el adiós. (Vicens, 2006, pp.73-74)

El reconocimiento familiar, lo que es la mirada del otro/otra con aprobación es una tecnología que esta racionalidad apremia para el continuo del hacerse en el género. La educación patriarcal enseña a buscar el consentimiento de los/las otros/otras, y el ser que se construye en el diario vivir desde esta racionalidad aprende a desear esta satisfacción. De acuerdo a estos postulados, analice- 
mos los sueños de José, quién pensó que sus nebulosas de mar contarían con el aplauso familiar. Regresar con la victoria alada por su valentía, por sus incursiones, eran sus sueños, sin embargo, su realidad era otra. Él era el único hijo varón y en esta masculinidad le correspondía asumir, en ausencia del padre o en la vejez de éste, el lugar del progenitor. Lo que es, en el caso de que el padre no estuviera presente en la familia o menguara en fuerzas, el hijo debía continuar siendo el padre simbólico, debía "cumplir" con el deber ser de proveedor, de ser la ley, la ciencia, la razón y el orden familiar. Las hermanas, en caso de que el padre no estuviera presente, deberían convertirse en hijas -simbólicas - y la madre, en la complejidad de esta moral, en la esposa simbólica del hijo.

La madre conoce el orden establecido por la racionalidad patriarcal, por ello su reclamo ante los sueños imprudentes de su hijo. ¿Cómo es que José se había atrevido a soñarse independiente de todos los deberes ser que su masculinidad conllevaba? La mirada de aprobación es una tecnología que norma ${ }^{15}$ y participa en el hacerse en la masculinidad tradicional o hegemónica. Contar con la aprobación de los/las otros/as es una forma de legitimar el continuo del hacerse. Para José tomar decisiones que im${ }^{15}$ Butler afirma que el “...reglamento es la
institucionalización del proceso mediante
el cual se regulan las personas" (2006, p.67),
en ese marco las normas que regulan el
género “.... exceden los propios casos que
encarnan” (2006, p.67) pero son asumidas
como condiciones reguladoras del ser y del
hacer. plicaran estar fuera de este reconocimiento familiar que tanto deseaba y que había aprendido a requerir significaba haber fallado ante los padres y ante sí mismo. El reconocimiento es entonces el mecanismo patriarcal que las instituciones, entre ellas la familia, enseñan para después a través de él, exigir conductas y decisiones. 
Ahora bien, José sí comprendió lo que debía elegir, quedarse en el continente para cuidar de sus hermanas, de su madre y posteriormente de su esposa e hijos, eran su presente y su futuro.

El reconocimiento que se aprende a buscar y a obtener a partir de la mirada de los/las otros/as está engarzado al mecanismo del miedo. La simple posibilidad de no vivir bajo la aprobación de los otros o el miedo de provocar que los padres no sean vistos con beneplácito por los actos de los hijos, es una herramienta que esta moral irradia y educa, porque a través de ella, disminuye las posibilidades de elección, se difuminan otras formas de vida y en ello, tiende caminos para el continuo de dicha moral. A través del hacerse en esta racionalidad y en ello en esta masculinidad, José García perpetúa estas exigencias en sus hijos y esposa. El continuo del deber ser se aviva. Él desea ser reconocido como un gran escritor, de ahí su tensión existencial porque no sabe que lo es. En esa frustración les exige a los hijos, a la esposa y a la amante que lo admiren, lo consideren y lo cuiden, porque finalmente él se inmoló por ellos. En la búsqueda del reconocimiento participa y continúa en el deber ser de hijo y padre. Ahora el precio que los demás deben pagar por la muerte de los anhelos de José García son la obediencia, el silencio y el continuo de la inmolación a las elecciones.

Desde este esquema, el texto presenta a un hombre reproductor de la masculinidad que esta racionalidad propone y a su vez, hace crítica, en términos de la consciencia que implica en el personaje estas exigencias. 
Y de ahí nace la trampa. Como no puedo vencerlo, dejo vivir en mis hijos, en mi mujer, en mí mismo a veces cerrando cobardemente los ojos, esa equivocación, esa mentira y me irrito cuando no me tratan con la tolerancia que los demás destinan para aquellos de quienes esperan algo importante y distinto. Yo mismo, que lo sé todo, me he sorprendido solapándome actitudes violentas y arbitrariedades que intento explicarme como propias de quien considera que tiene una más alta misión que la común y corriente de estar al cuidado y al servicio de su familia. Es un feo engaño, yo lo sé. Mi mujer, con su aterradora intuición, lo sabe también y, no obstante, se calla. (Vicens, 2006, pp.55-56)

José inmoló sus anhelos y deseos al someterse a la voluntad de los deseos de los padres. Así la racionalidad patriarcal continúa viviéndose a partir de sus actos y de las exigencias que él les pide a los hijos, esposa y amante. A pesar de la sumisión que ha vivido, existe una ventana que vislumbra horizontes de libertad y de crítica a dichas conductas propias de la masculinidad que eligió, éstas se presentan a partir de conocer los pensamientos que José de repente se sorprende haciendo. Se asombra reconociéndose violento, agresivo, prepotente, frustrado, asume que eligió por deber y no por deseo, que no desea la vida que tiene y que el vacío que siente es propio de alguien que se asumió a un prototipo de masculinidad que le ha implicado ser visto como el esquema a imitar, incluso él ha exigido 
ser visto así, pero el precio de este esquema han sido monedas de vida, de anhelos y de libertad que ha ido entregando.

\section{Los años falsos}

En 1982, luego de 25 años bajo el sello de Martín Casillas, Josefina publicó Los años falsos. Rápidamente la novela fue reconocida en Tabasco con el premio Juchimán de Plata. Esa tierra que, como decía Carlos Pellicer, era más su agua, que supo reconocer el surgimiento de una novela crítica del patriarcado y que narrada a manera de Bildungsroman (novela de aprendizaje), cuestiona la teoría y a la moral. Para la publicación de Los años falsos, la autora ya cuenta con 67 años, ha escrito guiones cinematográficos, ha recibido el permio Villaurrutia. La novela es entonces un texto de madurez y crítica donde entrelaza una propuesta narratológica por el desdoblamiento de los personajes, la representación de la muerte simbólica que causa el patriarcado y del poder que estas muertes otorgan. A partir de sustituir la preocupación del vacío, por la ansiedad de la muerte y la crítica al patriarcado (Domenella, 1998, p.194), Los años falsos van narrando los anhelos, las desilusiones, las renuncias y el proceso en la masculinidad tradicional de un adolescente que en el tiempo de una bala, se convierte en hijo, padre, hermano, esposo y dios.

Para este análisis, en la consciencia de que el texto está armado a manera de varios hilos fusionados, se estudiará la crítica moral y la muerte en el trenzado que Vicens los propone, buscando matizar estos aspectos, pero en la consciencia de que en la obra están en- 
treverados, reunidos como una totalidad que deviene en una propuesta que reproduce y crítica a dicha masculinidad, en un todo inseparable. En la novela los personajes se fusionan y se modifican entre sí. Alfonso Fernández es el heredero de la vida de Poncho Fernández. El tronido de una bala marca el inicio del final. El cierre de la educación patriarcal, donde Poncho Fernández, culmina el proceso de educación de su hijo. En la emulación que implica morir a partir de un aparente descuido al jugar con una pistola, objeto simbólico de la virilidad patriarcal, Alfonso Fernández deviene como marido de la madre, padre de las hermanas y cariñoso varón en la cama de la amante del padre.

En Los años falsos el íncipit se lee desde lo expuesto por Benveniste, ${ }^{16}$ donde presupone que el cambio ${ }^{16}$ Benveniste, Emile. (2004). "Estructura en el orden de los sujetos, en las voces de enuncia- $\begin{aligned} & \text { en Problemasde lingǘstica general, Méxi- } \\ & \text { co, Sigloxx. } 18 \text { Edición. }\end{aligned}$ ción, así como la conformación de los usos verbales, pueden darse con el deseo de causar interés o sorpresa. Por lo tanto, en "Todos hemos venido a verme" (Vicens, 1985, p.11), la comprensión lectora parece dificultarse, esto dado por la imposibilidad lingüística que esta frase conlleva. Si bien esta oración vivencialmente es imposible, no podemos venir a vernos, en la ficción se rompen los límites de lo real y se penetra, desde la primera oración en los bordes de lo simbólico y lo moral. En la aparente contradicción lingüística se expone el mayor logro narrativo de la obra, la trascendencia simbólica para la masculinidad que dicha racionalidad propone. En la enunciación se asume que la familia, a cuatro años de muerto Poncho Fernández, han ido a limpiar la tum- 
ba y a ponerle flores, pero que en dicho acto el sujeto de enunciación está vivo y de manera paralela está respirando bajo las lápidas de cubren la tumba. Es el vivo y el muerto, es por ello que mediante este uso lingüístico y simbólico el padre se diluye en el hijo.

A partir de introducir recursos estilísticos novedosos como las voces y las evocaciones, diferenciar al padre del hijo resulta complejo, dado que es el logro narrativo de la obra y es el enramado patriarcal que se logra mediante la educación de dicha moral. Este texto evidencia que las obras narrativas pueden ser tecnologías del género y a su vez hacer crítica a dicho sistema. En ella se exponen las ganancias de la educación de dicha moral y a su vez, a partir de imágenes que más parecen salidas de un sueño, cual evocaciones de la consciencia, se muestra la muerte y las consecuencias existenciales de inmolarse en vías de dicha masculinidad que están aderezadas por el deber ser, la educación, el reconocimiento y de la fuerza simbólica que el dolor de la madre viuda provoca.

La obra narra el Bildungsroman de Alfonso, el proceso de transformación de la vida de un adolescente de 14 años en adulto y, de manera simultánea, relata el proceso de conversión de Alfonso en Poncho, donde en un aparente retrotraerse del padre en el hijo, el que pervive es Poncho Fernández en el cuerpo del hijo. Son ambos y ninguno. Es la trascendencia perfecta de esta racionalidad, donde la que verdaderamente permanece es la masculinidad patriarcal.

Ahora me alegro de haberlo hecho; porque así quedó bien. Nuestro nombre, el de los dos, Luis Alfonso Fernández, sin 
más. Aunque las fechas no me correspondan a mí y el nombre casi no le pertenezca a él porque le fue disminuido y denigrado desde que nació: el niño "Ponchito", el joven "Poncho" y después, para todos y para siempre, "Poncho Fernández". Nadie le decía Luis Alfonso ni Luis, ni Alfonso, ni Fernández a secas. (...) No fui nunca el hijo de Luis Alfonso o del señor Fernández. Lo fui de "Poncho Fernández" siempre, desde aquel tiempo en que serlo era una especie de éxtasis, de trémula y secreta dicha, hasta este tiempo clausurado, que no me pertenece y que no transcurre. (Vicens, 1985, p.13)

En la novela se evidencia que la trascendencia que propone esta racionalidad para la masculinidad se logra desde los discursos. Poncho Fernández educó a su hijo para hacerse en esta masculinidad. Así se convirtió Poncho en el cuerpo de Alfonso y finalmente Poncho en el cuerpo del prototipo de esta masculinidad. De tal manera que al nacer comenzó el proceso preexistente a Alfonso. A partir de los ejemplos, los regalos, los premios, todo lo que implica la vida cotidiana, se reforzó lo que el padre había aprendido debía desear ser en el hijo. Para ello, la familia fue el elemento que dio fuerza a este sistema.

¡Es que no podría entenderlo, papá, no podía!

El Diputado cumpliendo tu último deseo, se hizo cargo de mí y me nombró su ayudante. 
— Haremos de ti otro "Poncho Fernández"

-me dijo.

Había que olvidar la escuela. Tú dijiste siempre: "el dinero es para gastarlo y los que ahorran son unos coyones que le tienen miedo a la vida”. Y como no eras coyón, no nos dejaste ni un centavo.

—ahora tú eres el señor de la casa— me dijo mi mamá el día que empecé a trabajar.

Pero no me dijo que desde ese mismo día dejaba de ser mi madre. Eso no me lo dijo. (Vicens, 1985, p.46)

Vivir bajo las nociones de dicha masculinidad implican ser visto como el hijo perfecto, querido por el padre, reconocido por la madre, amado y temido por las hermanas, todas tecnologías que implican desear ser visto con beneplácito y vivir bajo el miedo de no contar con ello. La obediencia a los deberes ser que dicha racionalidad propone para los hijos, conlleva a ser reconocido por los padres. Así los sueños que aparentan ser propios, pero que están cubiertos por el discurso, son espejismos de dicha masculinidad. Alfonso busca el reconocimiento del padre, de la madre, de los amigos del padre, y para ello, acepta morir, para convertirse en el hijo perfecto, con lo que asume el continuo del deber ser y corona la trascendencia de dicha racionalidad. Los valores que asume son los del padre y en ello, los del patriarcado. Renuncia a su ser para sí y se vuelve, lo que quieren que sea. 
Si bien a los catorce años es complejo mantener una postura crítica ante las exigencias que esta racionalidad demanda a través del padre, de la madre y las hermanas. Las verdaderas decisiones no se llevaron a cabo en el estruendo de la bala, sino se dieron cuando probó las delicias, en términos de poder, que dicha racionalidad aromatiza, a partir de negar al ser para sí. Deleites que son falsos espejos de poder y autonomía, ya que bocado tras bocado de dichos manjares, Alfonso diluye las posibilidades de experienciar otras formas de vivir la vida, y en ello, también resta posibilidades de existencia fuera de dicha moral. Dicho sea, asumido en vivir aquellos espejos de poder, penetra en el deber ser y con ello, Alfonso se disuelve en cada mordida. Este esquema moral naturaliza estructuras del deber ser para dichos géneros. Los varones en la familia son los encargados del orden y de proveer el dinero para que la familia subsista. En este orden, Poncho busca disculpar y legitimar, de manera simultánea, su falta de capacidad financiera y su hombría. Postulando que los que ahorran son coyones, así legitima una verdad escondida, que el ingreso de la familia está matizado por los gastos que él tiene derivados de la convivencia con los amigos, con las prostitutas y con la amante, pero todo bajo el aura de que él es muy hombre, nunca un cobarde.

Alfonso, para gozar de este poder que le otorga reconocimiento y le resta vida y autonomía, tuvo que hacer muchas renuncias. Una muy importante en términos de la normatividad de esta masculinidad fue alejarse de la atracción que siente por su amigo y demostrar frente a los amigos del padre, ahora sus compañeros de 
trabajo, que él es heterosexual y cumple con dicho imperativo categórico. Hacia el final de la novela surge un nuevo personaje, ya que Alfonso es ahora un desdoblado sujeto que puede dar vida y quitarla. Es el padre en el cuerpo del hijo y el hijo que se cree poderoso y que consciente del poder que ha adquirido a partir de las renuncias supone que puede dar vida al padre y a él. Iluso sujeto de dicha racionalidad. Ahora se presenta un personaje asumido en el prototipo que no vislumbra las cadenas que le atan porque la nebulosa de poder lo ha cegado.

Como dijimos, la novela a partir de la trenza narrativa funge como tecnología del género, a partir de describir las estructuras que los personajes experiencian para vivirse cada día en dicha racionalidad; para efectos de Poncho y Alfonso en la masculinidad tradicional. A su vez, a partir de las voces narrativas que muestran los pensamientos de Alfonso, somos invitados al área secreta del ser que se cuestiona, se debate y nos confiesa sus deseos, sus miedos y angustias. Es el adolescente que por los demás es reconocido como heterosexual, digno hijo y sustituto del padre, pero que se declara y nos pregunta, por qué todo lo sucedido, si él sólo quería seguir siendo hijo y que la madre le llevara un vaso con leche a la cama.

Las sensaciones ilusorias que proporcionan el sentirse el hijo predilecto del padre, el proveedor de los medios de subsistencia de la familia, el sustituto del padre en el trabajo y en la cama de la amante, el amigo de los amigos de Poncho Fernández, la renuncia al erotismo que le proporciona mirar al amigo, parecieran satisfacer las necesidades de Alfonso, pero paso a paso lo convierten en la 
expresión de la trascendencia de dicha masculinidad, la metafísica figura que fusiona al padre en el cuerpo del hijo. Donde pareciera que a través de tantas renuncias y obediencias el que murió fue Alfonso y surgió renacido Poncho, pero en la novela la que resurge es la racionalidad patriarcal en el cuerpo de un sujeto que se percibe todo poderoso, dador de vida y en apariencia capaz de mutar a Alfonso en Poncho, pero que desde hace muchos días mutiló a su ser para sí. A partir de las superposiciones simbólicas entre los personajes masculinos, el uso de voces discursivas que entrelazan la vida y la muerte, y borran los límites entre éstas y el surgimiento de un tercer personaje varón en el cuerpo de Alfonso, observamos cómo la autora bajo una propuesta narrativa novedosa, trenza la reproducción y la crítica a dicha masculinidad.

\section{Algunas consideraciones}

Desde esta lectura las preguntas sobre el vacío y las renuncias a la elección en aras de cumplir con el deber ser de la masculinidad tradicional son las guías de El Libro vacío. Mientras que para Los años falsos los cuestionamientos están en términos de los deberes de la masculinidad y la trascendencia de la racionalidad patriarcal. Como hemos señalado ambas novelas participan en la reproducción de la moral y la masculinidad de la racionalidad patriarcal y a su vez, motivan a la reflexión a través de plantear elementos críticos. José es un hombre aburrido de la vida, a partir de renunciar a aquellos sueños que tuvo en la juventud y de asumir el esquema que le dijeron debía representar. Ahora es un hombre que 
cumple con el deber ser que decidió seguir, pero que le ha llevado a una existencia poco satisfactoria, donde incluso reconoce que el amor que la esposa le profesa, no puede devolver con gratuidad, porque él hubiera elegido otra vida. Las voces narrativas que fusionan a Alfonso y Poncho Fernández evidencian una propuesta narratológica novedosa bajo la cual se muestra cómo se configura y trasciende la masculinidad tradicional. A partir de la creación narrativa de un ser que es Alfonso y Poncho, que es dios y cada uno de ellos por separado, se describe cómo los discursos participan en el continuo de los deberes ser del patriarcado. Finalmente podemos decir que ambas novelas, leídas desde esta metodología, son textos que nos motivan a la reflexión, que describen los deberes ser de la masculinidad patriarcal y a su vez participan en la deconstrucción de ésta.

\section{Bibliografía}

Amorós, C. (1991). Crítica a la razón patriarcal. Madrid: Anthropos.

Benveniste, E. (2004). Problemas de lingüística general. México: Siglo XXI.

ButLer, J. (2006). Deshacer el género. España: Paidós.

CANO, G. y RADKAU, V. (1989). Ganando espacios. Historias de vida: Guadalupe Zúniga, Alura Flores y Josefina Vicens, (1920-1940). México: UAMIztapalapa. (Colección Correspondencia).

- (1988). Lo privado y lo público o la mutación de los espacios (historias de mujeres 1920-1940). Recuperado de: https:// ideasfem.wordpress.com/textos/j/j03/). 
Castellanos, R. (2006). Los hijos una propiedad privada. En A. Reyes (comp), Mujer de palabras. Artículos rescatados de Rosario Castellanos. Volúmen II (pp. 238-241). México: CONACULTA, Lecturas Mexicanas. Castro, M. y Petterson, A. (Coords). (2006). Josefina Vicens. Un vacío siempre lleno. México: Tecnológico de Monterrey/CONACULTA-FONCA. Domenella, A. R. (1998). Muerte y patriarcado en Los años falsos de Josefina Vicens. En L. Campusano (coord.). Mujeres latinoamericanas del siglo xx. Historia y cultura. Tomo I (pp.191-204). México: Universidad Autónoma Metropolitana, Iztapalapa/ Casa de las Américas.

— (22 de noviembre de 1998). Un clásico marginal. La Jornada Semanal. Recuperado de: http://www.jornada.unam.mx/1998/11/22/semjosefina.html

FERNÁNDEZ, H. (2006). La sustancia vibrante del humanismo:

Josefina Vicens. En A. Saladino. (coord.). El pensamiento latinoamericano del siglo $\mathrm{xx}$ ante la condición humana. Recuperado de: https:// www.google.com.mx/webhp? sourceid = chromei n s t a n $\&$ i o n $=1 \&$ e s p v $=2 \&$ i e $=U T F$. $8 \# \mathrm{q}=$ josefina\%20vicens\%20y\%20la\%20sogem).

GONZÁLEZ, D. y TOlEDO, A. (1989). Josefina Vicens: la inminencia de la primer palabra. México: Ediciones sin nombre/Universidad del Claustro de Sor Juana.

INGARDEN, R. (1998). La obra de arte literaria. México: Taurus, UIA.

LAURETIS, T DE. (1996). La tecnología del género. Mora, (2), 6-34.

LinColn, I. (julio-septiembre 2011). Josefina Vicens ante el proceso creativo de El libro vacío y Los años falsos. La Colmena, (71), 34-39. 
LorenZANO, S. (2006). Josefina Vicens: sobrevivir por las palabras. En E. Urrutia (Coord.). Nueve escritoras mexicanas nacidas en la primera mitad del siglo XX y una revista (pp. 83-102). México: INMUJERES/COLMEX. NúÑEZ, G. (2016). Los estudios de género de los hombres y las masculinidades en México: reflexiones sobre su origen. La Ventana, 23(19), 30 61.

Paz, O. (1986). Carta prefacio de Octavio Paz. En J. Vicens. El libro vacío (pp. 7-8) México: Lecturas mexicanas.

SÁENZ, A. (2015). La crítica a la racionalidad patriarcal, un paradigma para pensar a los géneros. En V. Ávila y P. Suárez (Coords.). El género y la globalización en los debates de la Teoría Social Contemporánea (pp. 84109). México: UNAM.

- (2013). Los años falsos y El libro vacío: la ciudad, la muerte y los roles de género en Josefina Vicens. En-claves del ser humano, (13), 149-174.

- (2011). Una mirada a la racionalidad patriarcal en México en los años cincuenta y sesenta del siglo xx. Estudio de la moral en Los años falsos de Josefina Vicens. México: UMSNH/Plaza y Valdés.

Thompson, K. (Ed.). (2005). Ser hombre. Barcelona: Kairós, Biblioteca de la Nueva Conciencia.

Vicens, J. (2006). El libro vacío. Los años falsos. México: FCE.

— (1985). Los años falsos. México: Martín Casillas Editores. 